\title{
Bécquer en los Sonetos del amor oscuro de Federico García Lorca.
}

\section{Bécquer in the in Sonetos del amor oscuro by Federico García Lorca.}

\author{
Martín Eduardo García Calle \\ Universidad Científica del Sur / Universidad de Piura \\ Departamento de Cursos Básicos: Lengua y Literatura (PERÚ) \\ CE: martin e85@yahoo.es / mgarciaca@ucientifica.edu.pe ID ORCID: 0000-0002-5563-9421
}

DOI: $10.32870 /$ sincronia.axxiii.n76.17b19

Esta obra está bajo una Licencia Creative Commons Atribución-NoComercial 4.0 Internacional

Recibido: $25 / 03 / 2019$

Revisado: 28/04/2019

Aprobado: 07/06/2019

\section{RESUMEN}

Este artículo analiza las similitudes existentes entre la temática de las Rimas de Gustavo Adolfo Bécquer y los Sonetos del amor oscuro de Federico García Lorca. Desde mi punto de vista, Lorca al igual que Bécquer plasma el dolor por no ser correspondido cuyo final es idéntico: la muerte de la voz poética. A través de ejemplos intentaré justificar mi propuesta.

Palabras clave: Bécquer. Lorca. Intertextualidad. Desamor. Muerte.

\section{Abstract:}

This study analyzes the similarities existing around the theme of the Rhymes by Gustavo Adolfo Bécquer and the Sonnets of Dark Love by Federico García Lorca. In my opinion, Lorca becomes a imitator of Bécquer by writing in his sonnets the pain of not being reciprocated whose suffering lead to death. Through examples I will try to justify my proposal.

Keywords: Bécquer. Lorca. Intertextuality. Frustration. Death. 
Cayó sobre mi espíritu la noche en ira y en piedad se anegó el alma iy entonces comprendí por qué se llora y entonces comprendí por qué se mata! (Bécquer, 2013, p. 34)

Quiero llorar mi pena y te lo digo Para que tú me quieras y me llores En un anochecer de ruiseñores Con un puñal, con besos y contigo. (García, 1988, p. 303)

He creído oportuno empezar este trabajo citando la rima XLII de Bécquer y el soneto "El poeta dice la verdad" de Lorca, porque considero que estos versos son los que mejor representan mi propuesta: el desamor lleva a la muerte de la voz poética. ¿A qué se debe esta similitud en las Rimas y en los Sonetos? Mi hipótesis está en sus respectivas poesías: ambos poetas escriben acerca del dolor por no ser correspondidos; cuyas metáforas aluden a la muerte y a la decepción amorosa. Y también ambos tuvieron una vida amorosa desdichada y murieron de forma precoz. Además, lo que me motiva a realizar esta investigación es que (posiblemente) tanto Bécquer como Lorca son los poetas más universales de la literatura española del siglo XIX y XX, respectivamente. Coincido plenamente con aquellos que señalan a Bécquer como el poeta español más importante del siglo XIX: “[...] Este hombre se llamaba Gustavo Adolfo Bécquer. Es el más grande poeta de nuestro siglo XIX. Simboliza la Poesía" (Azorín, 1999, p. 249). Y de Lorca, algo similar: “Federico García Lorca está considerado como el poeta más popular de la lírica española del siglo XX" (Madrigal, 1998, p.71). 
La relación que establezco entre las Rimas y los Sonetos no han sido estudiadas a fondo por la crítica ${ }^{1}$; por tanto considero que este estudio es pionero al proponer la influencia de Bécquer en los Sonetos del amor oscuro de Lorca. Desde mi punto de vista, Bécquer en sus Rimas, es el poeta español que mejor representa los principales tópicos amorosos: mujer ángel, mujer fatal, y mujer inalcanzable.

\author{
Mujer ángel \\ Hoy los cielos y la tierra me sonríen \\ hoy llega hasta el fondo de mi alma el sol \\ hoy la he visto, la he visto y me ha mirado \\ ¡Hoy creo en Dios!
} (Bécquer, 2013, p. 52).

\title{
Mujer fatal
}

Como se arranca el hierro de una herida su amor de las entrañas me arranqué; aunque sentí al hacerlo que la vida ¡me arrancaba con él!

(Bécquer, 2013, p. 27).

\begin{abstract}
Mujer inalcanzable
Yo voy por un camino, ella por otro; pero, al pensar en nuestro mutuo amor, yo digo aún: - ¿Por qué callé aquel día? y ella dirá: - ¿Por qué no lloré yo?
\end{abstract} (Bécquer, 2013, p. 47).

\footnotetext{
${ }^{1}$ Si bien es cierto, hay mucha bibliografía en torno a la influencia de Bécquer en la Generación del 27: en Juan Ramón Jiménez, en Vicente Aleixandre, etc.; sin embargo, hay pocos estudios que indiquen una intertextualidad directa de Bécquer en Lorca. Uno de los pocos manuales es el de Blanc, M. (1997). Las rimas de Bécquer: su modernidad. Madrid, España: Editorial Pliegos.
} 
Por su parte, Lorca plasma en sus sonetos el mismo dolor al no ser correspondido (angustia que aumenta, en mi opinión, por su condición homosexual; él es consiente que encontrará el rechazo de la sociedad):

\author{
Yo te oculto llorando, perseguido \\ por una voz de penetrante acero
}

(García Lorca, 1988, p. 305).

Este trabajo pretende mostrar, a través de paralelismos, las semejanzas entre Bécquer y Lorca. A continuación, se realizará un breve recorrido biográfico para después centrarme exclusivamente en la intertextualidad.

\title{
1. ¿Vidas paralelas: escribieron lo que vivieron?
}

Gustavo Adolfo Bécquer nació en Sevilla el 17 de febrero de 1836 y murió en Madrid el 22 de diciembre de 1870. Quedó huérfano a muy temprana edad: a los 5 años falleció su padre y a los 11 su madre. Bécquer tuvo siete hermanos, pero el más cercano fue Valeriano (más que un hermano fue su gran amigo). Sus biógrafos ${ }^{2}$ aseguran que estuvieron muy unidos por lo que coinciden en señalar que la muerte de Valeriano (producida tres meses antes del deceso del poeta) fue un golpe psicológico muy doloroso que nuestro poeta no pudo superar y que, unido a su débil salud, precipitó su muerte. El legado de Bécquer son las Rimas y Leyendas, (1997 y 2011) obras que se publicaron al año siguiente de su fallecimiento (1871) gracias al empeño y a la generosidad de sus amigos $^{3}$.

Federico García Lorca nació en Granada, veintiocho años después de la muerte de Bécquer: el 5 de junio de 1898 y murió asesinado el 18 de agosto de 1936 (justo un siglo después del nacimiento de Bécquer). Su padre fue un próspero terrateniente y su madre fue una maestra de escuela. Tuvo cuatro hermanos y él fue el primogénito. En 1919 (con 21 años) viajó a Madrid y vivió

\footnotetext{
2 Brown, R. (1969); Rafael Montesinos (2011).

${ }^{3}$ Los amigos del poeta que demostraron con la publicación de sus obras un gesto de verdadera amistad hacia el compañero muerto fueron: Casado del Alisal, Narciso Campillo, Augusto Ferrán, y Ramón Rodríguez Correa.
} 
en la Residencia de Estudiantes. Allí entabló amistad con muchos poetas, escritores e intelectuales como: Juan Ramón Jiménez, Gerardo Diego, Pedro Salinas, Rafael Alberti, Salvador Dalí, etc. En 1929 viajó a Estados Unidos. Al año siguiente regresó a España y en 1931 creó un grupo de teatro universitario Ilamado "La Barraca". Entre sus principales producciones literarias destacaron: EI romancero gitano (1927), Bodas de sangre (1933), Poeta en Nueva York (obra póstuma publicada por su amigo José Bergamín ${ }^{4}$ en 1940), entre otras.

Aunque las similitudes en sus respectivas vidas, por si solas no constituyen un argumento sólido para fundamentar mi propuesta, considero que sí ayuda a mi tesis: encuentro cuatro paralelismos principales (desafortunados en el amor; fallecimientos prematuros; fama póstuma y la protección de un mecenas).

Bécquer fue desdichado en el amor. La crítica señala a Julia Espín ${ }^{5}$, a su hermana Josefina Espín ${ }^{6}$ y a su esposa Casta Esteban ${ }^{7}$ como las tres mujeres más importantes en el corazón del poeta, sin embargo, no fue feliz ni con Julia, ni con Josefina, ni con Casta. Por el lado de García Lorca, los especialistas señalan a Salvador Dalí ${ }^{8}$, Emilio Aladrén y a Rafael Rodríguez Rampún como los amores más importantes en la vida del poeta. Del mismo modo ninguno lo correspondió plenamente. Bécquer en la rima XXXVIII expresa su desazón -a modo de queja- por el amor no correspondido:

Dime, mujer, cuando el amor se olvida, ¿sabes tú a dónde va? (Bécquer, 2013, p. 28).

\footnotetext{
${ }^{4}$ El propio García Lorca le entregó el manuscrito a José Bergamín poco antes de morir: Eisenberg, D (1976). Poeta en Nueva York: historia y problemas de un texto de Lorca, Barcelona, España: Ariel.

5 No existe dudas en torno a Julia Espín como la principal musa de nuestro poeta. Hay un gran consenso entre los especialistas.

${ }^{6}$ El gran defensor de esta teoría es Rafael Montesinos. Para él, Josefina (la hermana menor de Julia) fue el gran amor de Bécquer y la inspiradora de la mayoría de sus versos: "Admito como posible que, en un principio, Gustavo estuviese enamorado de la seca y autoritaria Julia, y que después volviese los ojos hacia la dulce Josefina" (Bécquer, 2011, p. 28).

${ }^{7}$ Casta fue su legítima esposa, aunque el matrimonio no fue feliz debido a los problemas económicos y a la infidelidad de Casta (los biógrafos dudan de la paternidad de Bécquer en su tercer hijo).

${ }^{8}$ Actualmente existe información bien documentada sobre la relación que existió entre Dalí y Lorca. Gibson, I. (2016). Lorca-Dalí. El amor que no pudo ser. Barcelona, DeBolsillo.
} 
Lorca expresa su incomprensión por no ser feliz, pero a su manera. En el soneto "El amor duerme en el pecho del poeta" dice:

Tú nunca entenderás lo que te quiero

Porque duermes en mí y estás dormido

(García Lorca, 1988, p. 305).

Respecto a sus muertes; Bécquer falleció a los 34 años (víctima de una fuerte neumonía) y Lorca a los 38 (fusilado al empezar la Guerra Civil Española). Asimismo, ambos plasman en su obra poética la presencia de la muerte. Bécquer en la rima LVI:

$$
\begin{aligned}
& \text { Al ver mis horas de fiebre } \\
& \text { e insomnio lentas pasar, } \\
& \text { a la orilla de mi lecho, } \\
& \text { ¿quién se sentará? [...] } \\
& \text { Cuando la campana suene } \\
& \text { (si suena en mi funeral), } \\
& \text { una oración al oírla, } \\
& \text { ¿Quién murmurará? [...] } \\
& \text { (Bécquer, 2013, p. 50). }
\end{aligned}
$$

En el caso de Lorca, del mismo modo se observa de forma nítida el presagio de su muerte en el poema “Memento" del libro Poema del cante jondo (1931).

$$
\begin{gathered}
\text { Cuando yo me muera, } \\
\text { enterrarme con mi guitarra } \\
\text { bajo la arena. [...] } \\
\text { Cuando yo me muera, } \\
\text { Enterradme si queréis } \\
\text { en una veleta [...] } \\
\text { (García Lorca, 1988, p. 90). }
\end{gathered}
$$


Y en lo que concierne al reconocimiento literario, ambos poetas consiguieron la fama después de muertos (si bien es cierto, Lorca alcanzó la fama en vida, pero su figura cobró valor universal después de su asesinato). Eusebio Blasco, considerado como uno de los primeros biógrafos de Bécquer señala: "Porque, en honor a la verdad, ninguno de los que tomábamos el café cotidianamente con Bécquer en el Suizo viejo [...] ninguno, repito, creíamos ni podíamos sospechar que al año de muerto nuestro amigo sus versos recorrían el mundo [...]" (Blasco, 1886, p. 18). En el caso de la universalidad de Lorca, algo similar ocurre. "La MLA Bibliography, por ejemplo, muestra cerca de 1000 estudios dedicados a Federico García Lorca y su obra en sólo los últimos 15 años". (Curry, 2012, p. 35). Asimismo, otro punto en común es que ambos escritores gozaron del afecto y de la protección de un mecenas. Luis González Bravo fue el protector de Bécquer y en el caso de Lorca lo fue Fernando de los Ríos.

En el caso de las diferencias, Bécquer tuvo una infancia desdichada marcada por su condición de huérfano, mientras que los primeros años de Lorca fueron apacibles y agradables debido a la compañía de sus hermanos y de sus padres. Por otro lado, Bécquer no fue a la universidad, Lorca sí (aunque con grandes dificultades consigue -después de 8 años- su título de abogado. Grado académico que no le sirvió porque nunca ejerció dicha profesión). Gustavo se ganó la vida publicando artículos, cuentos y relatos en diversos periódicos; Federico tuvo el apoyo económico de sus padres y después, gracias al éxito de sus obras de teatro, pudo valerse por sus propios medios. Asimismo, las condiciones sexuales de ambos vates fueron opuestas: Bécquer fue heterosexual, contrajo matrimonio y tuvo 3 hijos; mientras que Lorca fue homosexual, no tuvo hijos y nunca se casó. 


\section{Intertextualidad: Bécquer en Lorca}

Otro rasgo común de las rimas de Bécquer y los sonetos de Lorca es que ambas obras -en su totalidad- se publicaron de forma póstuma. Bécquer, en vida, solo publicó dieciséis rimas ${ }^{9}$; por su parte Lorca escribió sus sonetos entre 1935-1936 aproximadamente ${ }^{10}$. Con relación a la presencia de otros autores en estas obras; también se pueden establecer nexos. Por ejemplo, la de Dante Alighieri. En la rima 29 aparecen las huellas de Dante: “Creación de Dante era el libro/ era su Infierno/Cuando a él bajamos los ojos/yo dije trémulo [...]" (Alighieri, 1870, p.1). En el caso del soneto Ay voz secreta del amor oscuro: "Huye de mí caliente voz de hielo/no me quieras perder en la maleza/donde sin fruto gime carne y cielo"11 (De Lama, 2006, p.161).

Las Rimas denotan sencillez, brevedad, con un estilo intimista, confidencial y confesional. Tal vez esa es la razón principal por lo que perduran en el tiempo y también por haber llegado a todo tipo de lectores sin distinguir su grado de instrucción académica o su situación económica. Respecto al orden de las Rimas, muerto el poeta, sus amigos consideraron oportuno dividir los poemas de acuerdo con su temática. Las estructuraron en cuatro grupos: en el primer grupo el tema central es la poesía; el segundo grupo es el amor; el tercer grupo es el dolor y el desengaño; y el último grupo es de tema variado en el que también aparecen algunos poemas sobre la muerte. En este trabajo se analiza las rimas del tercer grupo: "Los editores agruparon en tercer lugar las rimas de la ruptura y del amor perdido (XXX al LIV), las más numerosas" (Pageard, 1971, p.3). Y algunas del cuarto grupo: "recoge la depuración última de la experiencia vivida por el poeta, realizada sobre todo en la soledad en que queda frente al mundo y a la muerte" (López, 1997, p. 29).

\footnotetext{
${ }^{9}$ Los estudiosos coinciden en afirmar que la primera rima la publicó el 17 de diciembre de 1859 en la revista El Nene con el título "Imitación a Byron": "Tu pupila es azul, y cuando ríes/su claridad suave me recuerda/el trémulo fulgor de la mañana/que en el mar se refleja" [...]. La crítica ha detectado que: "ninguna de las rimas que hoy podríamos calificar como fundamentales figuran entre esas dieciséis poesías. Ni siquiera las dos más famosas del siglo XIX (la de la soledad de los muertos y la de las golondrinas)". (Montesinos, 2011, p.30).

${ }^{10}$ Ian Gibson, el biógrafo más reconocido de Lorca, señala que el poeta escribió dichos sonetos en servilletas de un hotel de Valencia y que no los publicó en vida debido a su asesinato. (Gibson, 1987, p.394)

${ }^{11}$ Sugiero que en estos versos existe una intertextualidad con "El Infierno" de la Divina Comedia de Dante Alighieri: "Hallábame en la mitad de la carrera de nuestra vida/cuando me vi en medio de una oscura selva/ [...] No es de seguro mucho más penoso el recuerdo de la muerte". (Alighieri, 1870, p.1).
} 
Los Sonetos de Lorca fueron publicados en el periódico $A B C$ el 17 de marzo de 1984 gracias a diversos estudiosos y a la familia del poeta que finalmente aceptó su publicación (meses antes, en noviembre de 1983 circularon ediciones piratas). Este poemario consta de once sonetos cuyo tema principal es el dolor, el desengaño y el sufrimiento por el amor no correspondido. Asimismo, un hecho interesante a tener en cuenta es la polémica ${ }^{12}$ que en su día generó el título del poemario.

Veamos, pues, las principales analogías:

\section{Rima 37}

Antes que tú me moriré; escondido en las entrañas ya

el hierro llevo con que abrió tu mano

la ancha herida mortal.

Antes que tú me moriré; y mi espíritu

en su empeño tenaz,

se sentará a las puertas de la muerte,

esperándote allá

$[\ldots]$

(Bécquer, 2013, p. 39).

Estos versos expresan congoja, angustia, resentimiento y dolor. Se nota claramente que la pena por no ser correspondido producirá la muerte en la voz poética. Asimismo, se observa la queja del poeta que culpa a la persona amada el hacerle daño. En el caso de Lorca se expresa algo similar:

\section{Llagas de amor}

Esta luz, este fuego que devora.

Este paisaje gris que me rodea

Este dolor por una sola idea.

Esta angustia de cielo, mundo y hora.

\footnotetext{
${ }^{12}$ La familia intentó eliminar el adjetivo "oscuro" de los Sonetos con el fin de evitar cualquier alusión a la homosexualidad de Federico.
} 
Son guirnalda de amor, cama de herido.

Donde sin sueño, sueño tu presencia

Entre las ruinas de mi pecho hundido.

\title{
[...]
}

(García Lorca, 1988, p. 402).

\author{
Rima 42 \\ [...] \\ ¿Qué tiempo estuve así? No sé; al dejarme \\ la embriaguez horrible del dolor, \\ expiraba la luz y en mis balcones \\ reía el sol. \\ Ni sé tampoco en tan terribles horas \\ En qué pensaba o qué pasó por mí: \\ Sólo recuerdo que lloré y maldije, \\ Y que en aquella noche envejecí.
}

(Bécquer, 2013, p. 43).

Esta rima refleja el dolor del poeta. Deja una duda en el lector respecto a la posibilidad de un suicidio: "en qué pensaba o qué pasó por mí". La poesía finaliza con una imagen preciosa: "en aquella noche envejecí" (Bécquer, 2013, p.43). Como lector siento tan palpable el dolor del poeta por lo que creo que ese dolor existió; caso contrario sería menos emotivo porque (desde mi punto de vista) solamente alguien que ha experimentado ese sentimiento puede plasmarlo de forma tan nítida. Lorca, por su parte, también deja abierta la "puerta" del suicidio en su voz poética:

\section{Soneto de la dulce queja}

$$
\text { [...] }
$$

Si tú eres el tesoro oculto mío

Si eres mi cruz y mi dolor mojado 
Si soy el perro de tu señorío.

No me dejes perder lo que he ganado

Y decora las aguas de tu río

con hojas de mi otoño enajenado.

(García Lorca, 1988, p. 251).

\author{
Rima 46 \\ Me ha herido recatándose en las sombras, \\ Sellando con un beso su traición. \\ Los brazos me echó al cuello, y, por la espalda, \\ partióme a sangre fría el corazón. \\ Y ella prosigue alegre su camino, \\ Feliz, risueña, impávida. ¿Y por qué? \\ Porque no brota sangre de la herida. \\ porque el muerto está en pie. \\ (Bécquer, 2013, p. 72).
}

Este poema es desgarrador y doloroso. Muestra lo desdichado que fue nuestro poeta en el amor. Interpreto que esta rima está dedicada a su esposa por su infidelidad. En lo meramente poético se observa la figura de la mujer fatal: "traición" (v. 2); "partióme ... el corazón" (v.4); "feliz" (v.6). Considero que la voz poética aún no quiere morir; desea resistir el golpe para no darle la razón a "aquella" que describe como: "feliz, risueña, impávida". En el caso de Lorca, también se observa una actitud similar:

\title{
Noche del amor insomne
}

Noche arriba los dos con luna llena

yo me puse a llorar y tú reías

tu desdén era un Dios. Las quejas mías 
momentos y palomas en cadena.

Y el sol entró por el balcón cerrado

y el coral de la vida abrió su rama

sobre mi corazón amortajado

(García Lorca, 1988, p. 306).

\section{Rima 52}

Olas gigantes que os rompéis bramando en las playas desiertas y remotas, envuelto entre las sábana de espumas, ¡llevadme con vosotras!

Llevadme, por piedad, a donde el vértigo con la razón me arranque la memoria. ¡Por piedad! ¡Tengo miedo de quedarme con mi dolor a solas!

(Bécquer, 2013, p. 43).

Esta rima es una de las que mejor expresan el dolor por no ser correspondido. Creo que ya es tan insoportable para el poeta que lo mejor es morir para evitar más sufrimiento. Bécquer quiere que la naturaleza "me arranque la memoria", es decir, quiere olvidar. Considero que en su interior guarda un recuerdo atroz (quizás una humillación; tal vez una infidelidad). El poema termina con una impactante personificación: “¡Por piedad! ¡Tengo miedo de quedarme con mi dolor a solas”! Lorca, a su vez, en su soneto plasma su dolor sugiriendo que, si su amante no le corresponde, lo mejor será morir.

\section{Soneto de la carta}

Amor de mis entrañas, viva muerte 
en vano espero tu palabra escrita

y pienso con la flor que se marchita

que si vivo sin mí quiero perderte.

\section{$[\ldots]$}

Llena, pues, de palabra mi locura

o déjame vivir en mi serena

noche del alma para siempre oscura.

(García Lorca, 1981, p. 223).

\section{Conclusiones}

La crítica ha analizado la intertextualidad de diferentes autores ${ }^{13}$ en los Sonetos del amor oscuro de Lorca, pero no se ha detenido en estudiar la presencia de Bécquer. Como se ha intentado demostrar en este trabajo, existen muchas similitudes entre la temática de las Rimas y los Sonetos. El principal nexo, desde mi punto de vista, es el dolor y el desamor que conllevan a la muerte. Resulta obvio señalar que Lorca leyó y conoció la poesía de Bécquer, pero resulta poco probable que Lorca escribiera sus sonetos con la intención de imitar las rimas o de hacerle un homenaje ${ }^{14}$. Quizás otras páginas de la literatura en lengua española se hubieran escrito si Julia Espín hubiese correspondido a Gustavo Adolfo y Rafael Rodríguez a Federico. Del mismo modo, si Bécquer no hubiese sido tan pobre ni tan débil en su salud; y Lorca hubiera conseguido escapar de la Guerra Civil Española, otra... hubiera sido la historia.

\section{Referencias}

Alighieri, D. (1870). La Divina Comedia. Barcelona: Montaner y Simón Editores.

Azorín (1919). La voluntad. Madrid: Renacimiento.

Blasco, E. (1886). Mis contemporáneos. Madrid: Editorial de Francisco Álvarez.

\footnotetext{
${ }^{13}$ La mayoría de especialistas sostienen que existen reminiscencias de autores como Dante Alighieri, Franceso Petrarca, San Juan de la Cruz, Góngora, Quevedo, entre otros.

${ }^{14}$ Lo que sí les consta a los lorquistas es el homenaje a Góngora. El mejor ejemplo es el "Soneto gongorino en que el poeta manda a su amor una paloma".
} 
Bécquer, G. (1997). Rimas y Leyendas. (Edición de Francisco López Estrada y María Teresa López GarcíaBerdoy). Madrid: CSIC.

Bécquer, G. (2011). Rimas y Leyendas. (Edición de Rafael Montesinos). Madrid: Cátedra.

Bécquer, G. (2013). Rimas y Leyendas. Madrid, España: Editorial Editex

Brown, R. (1969). La fama de Bécquer: nuevos datos, Revista de Filología Española, vol. LII, núm 1-4, pp. 525535.

Curry, R. (2012). El espíritu de modernidad en Federico García Lorca: dramatismo lírico y lirismo dramático, Revista de investigación y Crítica estética. 10, pp. 35-44.

De Lama, Victor (2006). Sonetos de amor: selección de 150 sonetos en lengua española. Madrid: EDAF.

Duque, A. (2012). La sombra de Bécquer, Boletín de la Real academia Sevillana de Buenas Letras, 40, p. 465.

García, F. (1988). Antología comentada. Madrid, España: Ediciones Latorre.

Gibson, I. (1987). Federico García Lorca 2. De Nueva York a Fuente Grande (1929-1936), Barcelona, Ediciones Grijalbo.

Gibson, I. (2016). Lorca-Dalí. El amor que no pudo ser. Barcelona, DeBolsillo.

López, M. (1997). Rimas y Leyendas. Madrid, Espasa Calpe.

Madrigal, H. (1998). Entre espejos, Guatemala, Nacional Impresora.

Pageard, R. (1971). Rimas de Gustavo Adolfo Bécquer. Madrid, Centro Superior de Investigaciones Científicas. 